Supporting Information for:

\title{
Multi-Iron Silicotungstates: Synthesis, Characterization, and Stability Studies of Polyoxometalate Dimers
}

Travis M. Anderson, Wade A. Neiwert, Kenneth I. Hardcastle, and Craig L. Hill $^{*}$

Department of Chemistry, Emory University, Atlanta, Georgia, 30322

\section{Table of Contents:}

Figure S1. Polyhedral representations of $(\mathbf{A})\left[\mathrm{Na}_{10}\left(\beta-\mathrm{SiW}_{9} \mathrm{O}_{34}\right)_{2}\right]^{10-}$ (reference 11), (B) $\left[\mathrm{Na}_{8}\left(\beta-\mathrm{PW}_{9} \mathrm{O}_{34}\right)_{2}\right]^{10-}($ reference 14$)$, and $(\mathrm{C})\left[\mathrm{K}_{3}\left(\alpha-\mathrm{Si}_{2} \mathrm{~W}_{18} \mathrm{O}_{66}\right)\right]^{13-}$ (reference 13).

Figure S2. Thermal ellipsoid plot (50\% probability surfaces) for [ $\alpha$ $\left.\left.\mathrm{SiFe}_{3} \mathrm{~W}_{9}(\mathrm{OH})_{3} \mathrm{O}_{34}\right)_{2}(\mathrm{OH})_{3}\right]^{11-}(\mathbf{1})$.

Figure S3. Thermal ellipsoid plot (50\% probability surfaces) for [( $\alpha$ $\left.\left.\mathrm{Si}\left(\mathrm{FeOH}_{2}\right)_{2} \mathrm{FeW}_{9}(\mathrm{OH})_{3} \mathrm{O}_{34}\right)_{2}\right]^{8-}$ (2). 
Figure S1.

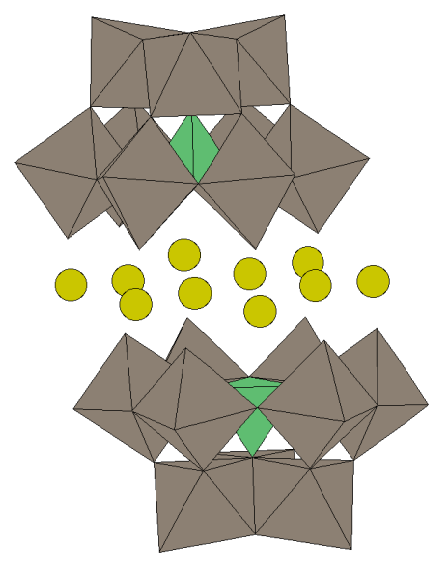

A

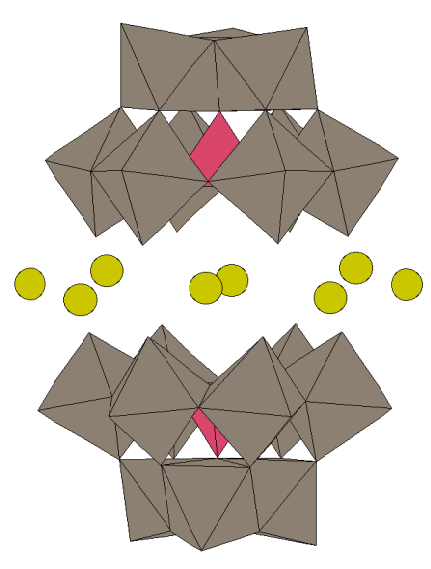

B

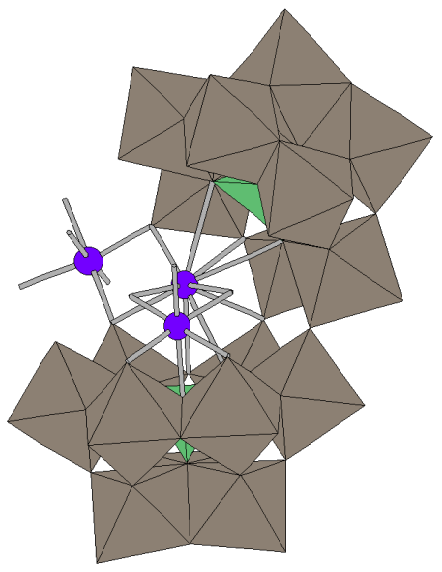

C 
Figure S2.

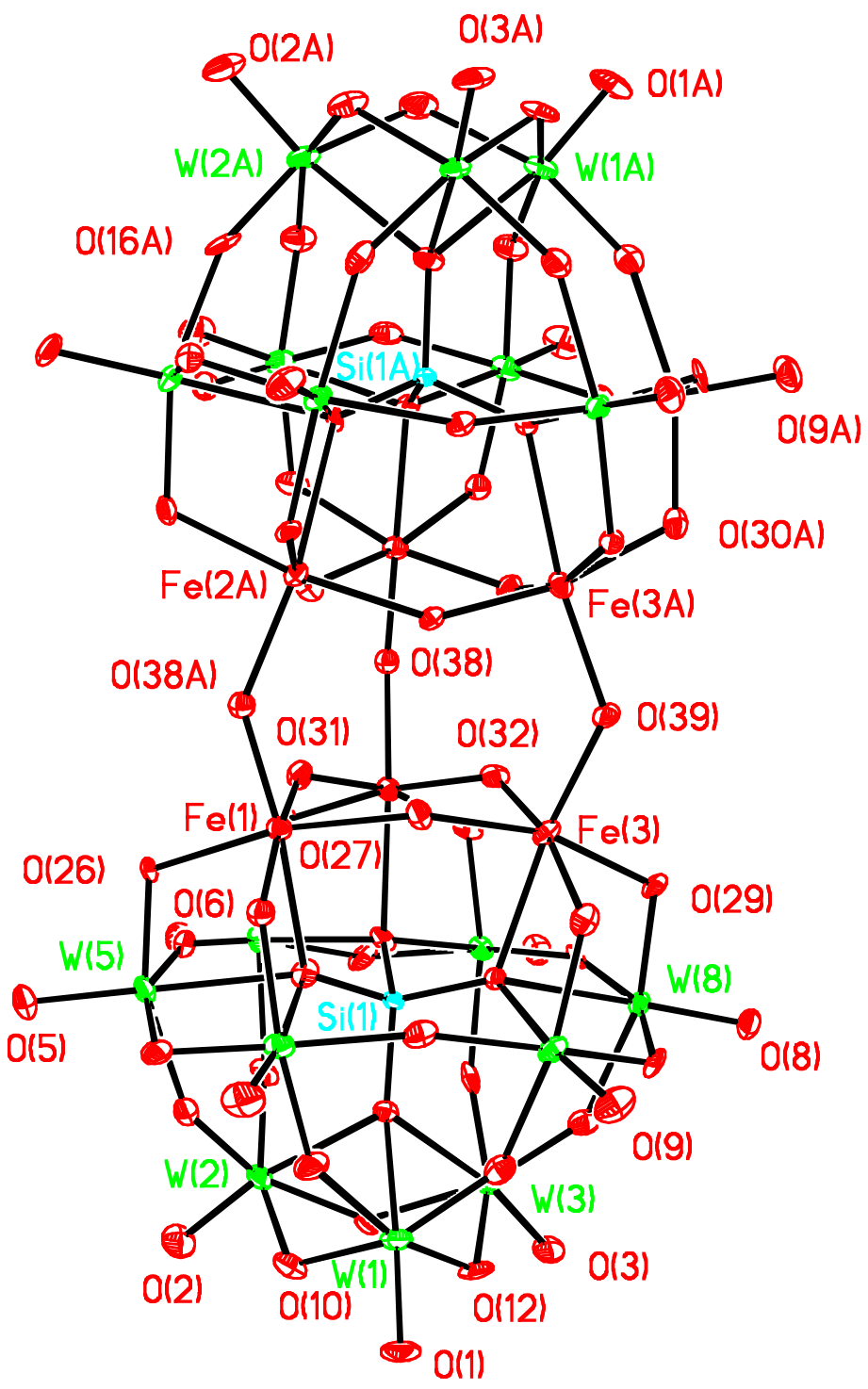


Figure S3.

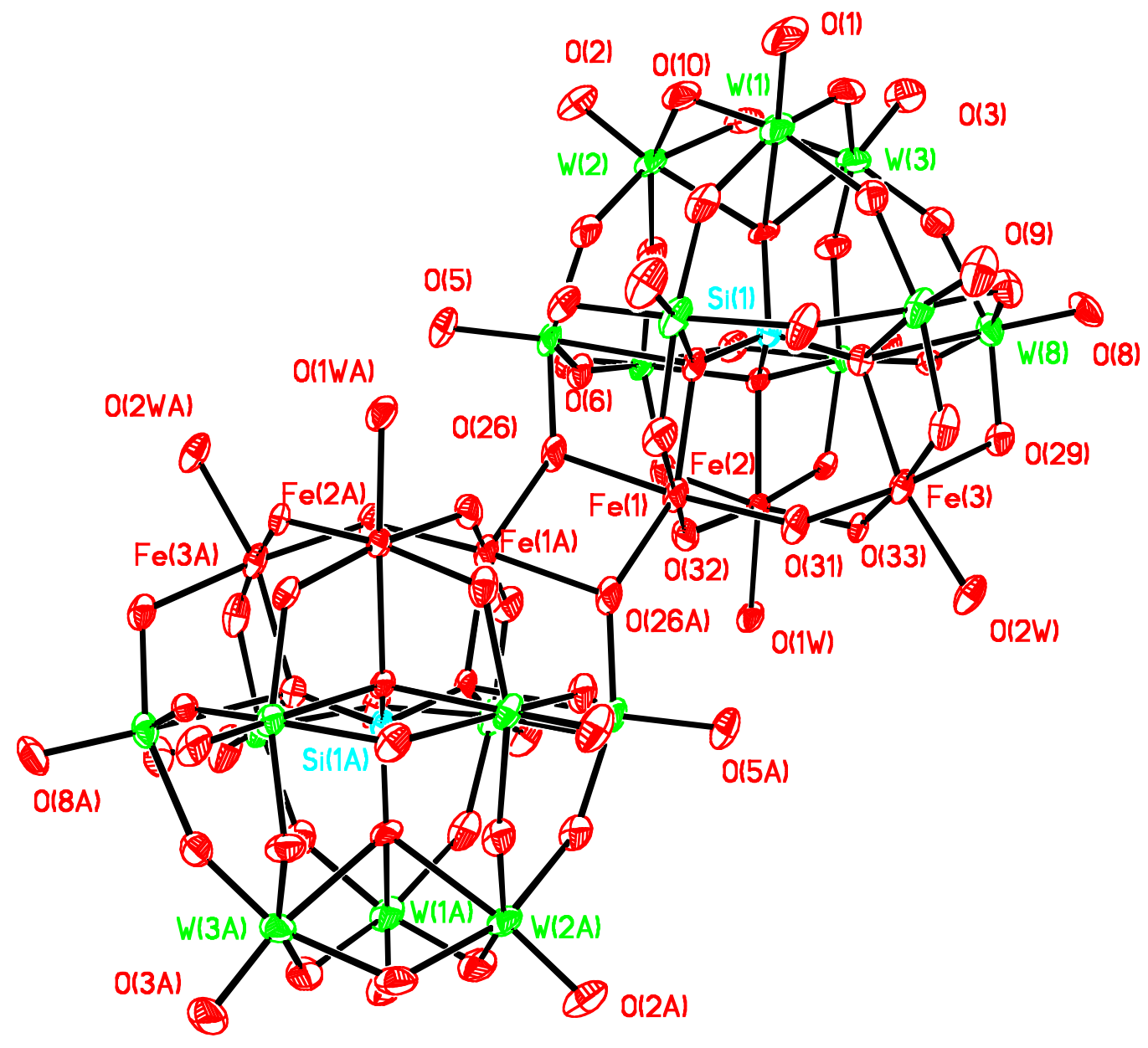

